\title{
Relation between Feeding Types and Surgical Wound Healing of Neonates
}

Faransa A Ahmed Prof. Elham M Ahmed, Dr.Ibrahim A Ibrahim, Dr. Asmaa Abd El-Aziz M Hussein

Pediatric Nursing, Faculty of Nursing- Assiut University

Pediatric Nursing, Faculty of Nursing - Cairo University

Pediatric Surgery, Faculty of Medicine- Assiut University

Pediatric Nursing, Faculty of Nursing- Assiut University

\begin{abstract}
Background: Breast milk has antimicrobial and healing properties that actually can help the wound healing. Surgical neonates are at a much higher risk for malnutrition as a result of increased metabolic demands from surgery, nutrient losses, and sepsis. Many methods of feeding are used postoperatively for neonates; oral feeding (breast milk or formula milk), enteral, or parenteral feeding. Aim of this work was to assess the relation between feeding types and surgical wound healing of neonates after. Methods and materials: Comparative descriptive research design was used to carry out this study. It comprised 100 neonates aged less than one month, they were divided into two equal groups as the following: Group 1: received breast milk feeding, Group 2: received formula milk feeding. Tools were developed by the researcher, after that the researcher fulfill assessment sheet and took the photographs were taken by the researcher on the 7 th postoperative day and reassessed for second time on the 14th day. Results: Out of the included neonates received breast milk feeding, $78 \%$ were boys, while $22 \%$ were girls. Also in the formula-feeding neonates, the majority (58\%) of formula feeding neonates' wounds were inflamed, while less than one third $(30 \%)$ of breast milk feeding neonates' wounds were inflamed during the 7 th day. On the other hand $38 \%$ of formula fed neonates' wounds were inflamed, while only $8 \%$ of breast milk feeding neonates' wounds were inflamed during the 14th day. Conclusion, neonates received breast milk feeding have rapid sound healing, less wound inflammation and receiving more number of daily feeding than formula feeding neonates.
\end{abstract}

\section{Key Words: Wound Healing, Preoperative Feeding, Postoperative Feeding, Neonatal Feeding.}

\section{Introduction}

Breast milk feeding remains the optimal method for nutritional support of the healthy neonate. In addition to fostering bonding between the mother and her child, breast milk provides optimal nutrient content to support growth and provides immunoactive substrates (Ziegler et al., 2003 \& Sanchez, 2007).

At birth, the neonate has substantial nutritional demands because of the high metabolic rate and the rapid growth and development. Surgical neonates are at a much higher risk for malnutrition as a result of increased metabolic demands from surgery, nutrient losses, and sepsis. Many methods of feeding are used postoperatively for neonates; oral feeding (breast or formula milk), enteral, or parenteral feeding (Shulman and Phillips, 2008).

Wound healing progresse through four phases: hemostasis, inflammation, proliferation, and remodeling. Nutrition plays a significant part in wound healing since it enables optimal healing to occur. Proper nutrition enhances the body's ability to regain its balance (Browne et al., 2007). Wound infection can cause illness, anxiety, increase patient discomfort and can lead to death. It is estimated that surgical wound infections result in an increased length of hospital stay by about 7-10 days (Duque et al., 2003).
Nurses who care for children with wounds should develop an understanding of wound care in order to expedite wound healing, prevent infection,

promote accurate communication both written and verbally, provide patient comfort, and prevent the development of institution-acquired wounds (Letizia et. al, 2006).

Significance Of The Study

Breast milk has antimicrobial and healing properties that actually can help the wound healing. The importance of breast milk feeding must be identified to nurses and parents. Mothers should be encouraged to maintain breast milk feeding during the postoperative period if oral feeding is allowed, in order to promote wound healing.

\section{Aim Of The Study}

The aim of this study was to assess the relation between feeding types and surgical wound healing of neonates.

\section{HYPOTHESIS}

Neonates who will receive breast milk are experiencing rapid wound healing more than those who will receive formula milk. 


\section{SUBJECTS AND METHODS}

\section{Research design:-}

Comparative descriptive research design was used to carry out this study to fit the nature of the problem under investigation.

\section{Setting:-}

The study was conduct in the Pediatric Surgical Unit at Assiut Pediatric University Hospital.

\section{Subjects:}

The study subjects included 100 neonates who were selected according to the following criteria:

\section{Inclusion Criteria :}

Both sexes, full term neonate up to one month of age.

Postoperative for 3 days.

\section{Exclusion Criteria :}

Neonates with medical problems as diabetics and heart diseases were excluded from the study subject.

(The neonate were divided randomly into two equal groups, each group included 50 neonates; group one received breast milk feeding and group two received formula milk feeding).

Tools:-

Two tools were used in this study.

Tool one: Assessment sheet for neonate:

It was developed by the researcher after reviewing of literature and consists of two parts:

Part one: Demographic and clinical data about neonate and his/her parents such as gestational age, birth weight, sex, and their diagnosis.

Part two: Child's food consumption pattern (preoperative and postoperative): such as, number of feeds / day, type of milk (formula or breast milk), and route of feeding.

Tool two: Observation sheet which included surgical wound healing criteria; sound healing, wound inflammation or redness, wound discharge, gapping of wound, burst abdomen, or incisional hernia. Wound's photographs were taken.

\section{Data collection:}

- Tools were developed by the researcher after reviewing of literature. Then the contents of the assessment sheet of wound healing were given to a panel of five pediatric surgeons and pediatric nurses with more than five years experience to determine the content validity.

- Permission was obtained from the director of Pediatric Surgical Unit to collected the necessary data

\section{- Pilot study:}

A pilot study was carried out on 10 neonates who were fulfilling the criteria of the study to evaluate the content of the questionnaire and assessment sheet and to estimate the time needed for answering the questions. The pilot study was subjects of the pilot study were excluded from the study sample.

- Mothers were interviewed individually where the study objective was explained and informed consent was obtained to collect the desired data. When interviewing the mothers, the investigator started by introducing herself explaining the purpose of the study, on the day of operation (before the neonate's operation) to assess the preoperative feeding.

\section{Field of the work}

- The field work was carried out through a period of 12 months from January 2009 to January 2010 .

- The time taken for filling each sheet ranged from $10-15$ minutes that is depending upon the response of the mother.

- All the neonates of the two groups were reassessment for wound healing during follow up at 7 th and 14th days of operation.

- Photographs were taken by the researcher on $7^{\text {th }}$ postoperative day and reassessed for second time on $14^{\text {th }}$ day.

Data analysis:

Collected data were revised and coded for computerized data entry. Data were then verified prior to statistical analysis. Statistical methods were applied including descriptive statistics as; (frequency, percentage, mean, and standard deviation), Z-test and Chi-squire $\left(\mathrm{x}^{2}\right)$ were used. $\mathrm{P}$ values were considered as statistically significant when less than 0.05 .

Ethical considerations:

Consent was taken from every mother and mothers were reassured that the information obtained will be confidential, and used only for the purpose of the study.

\section{Limitations of the study:}

Shortage in number of full term gestation and milk feeding newborns (breast milk feeding and formula feed newborns) postoperative at Neonate Intensive Care Unit (NICU) was found. 


\section{Results:}

Table (1): Distribution of breast milk feeding and formula feeding neonates according to their gestational age, birth weight, and sex.

\begin{tabular}{|l|c|c|c|c|}
\hline \multirow{2}{*}{ Items } & \multicolumn{2}{|c|}{ Breast milk } & \multicolumn{2}{c|}{ Formula milk } \\
\cline { 2 - 5 } & No. & \% & No. & \% \\
\hline Gestational Age: & & & & \\
<41 weeks & 18 & 36 & 22 & 44 \\
$41-$ weeks & 22 & 44 & 24 & 48 \\
$>42-$ weeks & 10 & 20 & 4 & 8 \\
\hline Total: & 50 & 100 & 50 & 100 \\
\hline Birth Weight: & & & & \\
$3.400 \mathrm{~kg}-$ & 20 & 40 & 8 & 16 \\
$3.700 \mathrm{~kg}-$ & 18 & 36 & 14 & 28 \\
$>4 \mathrm{~kg}$ & 12 & 24 & 28 & 56 \\
\hline Total: & 50 & 100 & 50 & 100 \\
\hline Sex: & & & & \\
Male & 39 & 78 & 32 & 64 \\
Female & 11 & 22 & 18 & 36 \\
\hline Total: & 50 & 100 & 50 & 100 \\
\hline
\end{tabular}

Table (2): Distribution of breast milk feeding and formula feeding neonates according to their diagnosis.

\begin{tabular}{|l|c|c|c|c|}
\hline \multirow{2}{*}{ Diagnosis } & \multicolumn{2}{|c|}{ Breast milk } & \multicolumn{2}{c|}{ Formula milk } \\
\cline { 2 - 5 } & No. & \% & No. & \% \\
\hline 1) Congenital & 41 & 82 & 33 & 66 \\
2) Acquired & 9 & 18 & 17 & 34 \\
\hline Total: & 50 & 100 & 50 & 100 \\
\hline Types of disorders: & & & & \\
1) Congenital & & & & \\
- Duodenal atresia & 10 & 24.4 & 5 & 15.2 \\
- Ileal atresia & 5 & 12.2 & 4 & 12.1 \\
- Hirschsprung's disease & 11 & 26.8 & 8 & 24.2 \\
- Anal atresia and anorectal malformations & 15 & 36.6 & 16 & 48.5 \\
\hline Total: & 41 & 100 & 33 & 100 \\
\hline 2) Acquired & & & & \\
- Intussusception & 8 & 88.9 & 15 & 88.2 \\
- Trauma & 1 & 11.1 & 2 & 11.8 \\
\hline Total: & 9 & 100 & 17 & 100 \\
\hline
\end{tabular}

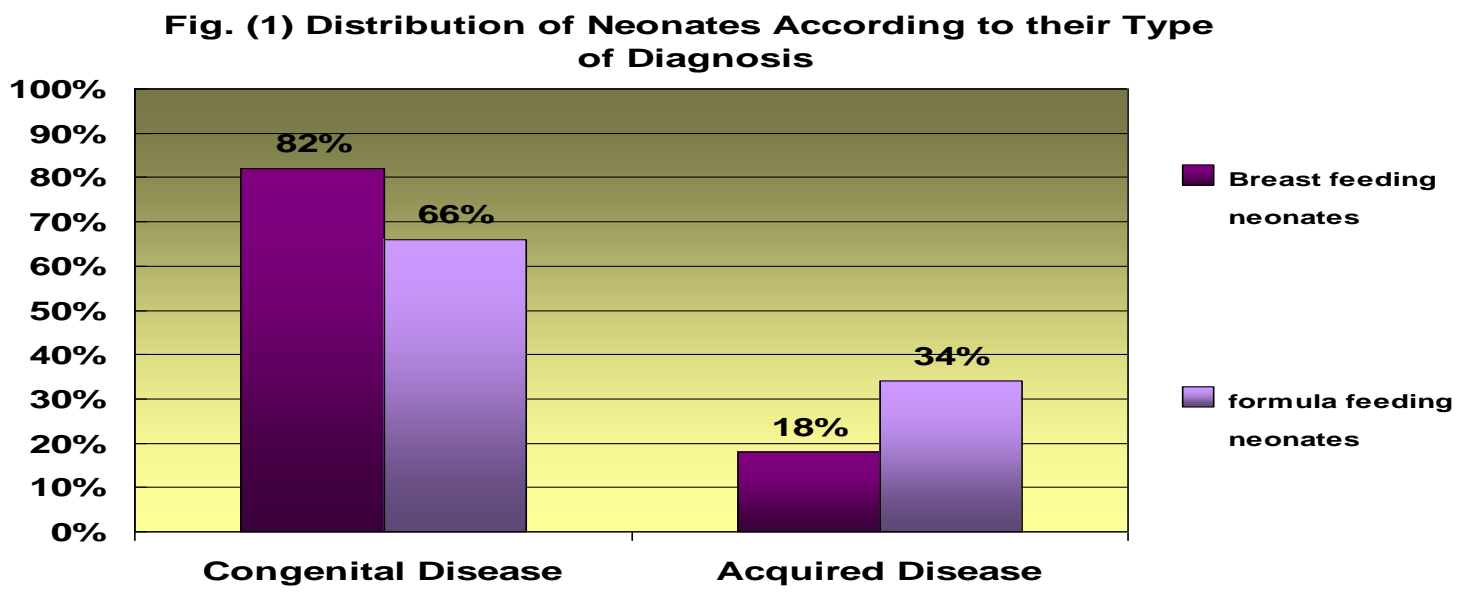


Table (3): Relationship between sound healing of neonates' wounds and their type of feeding during $7^{\text {th }}$ and $14^{\text {th }}$ day

\begin{tabular}{|c|c|c|c|c|c|c|}
\hline \multirow[t]{2}{*}{$\underline{\text { Items }}$} & \multicolumn{2}{|c|}{ Breast milk } & \multicolumn{2}{|c|}{ Formula milk } & \multirow{2}{*}{ Z.Test } & \multirow[b]{2}{*}{ P.Value } \\
\hline & No. & $\%$ & No. & $\%$ & & \\
\hline \multicolumn{7}{|l|}{$\begin{array}{l}\text { A. Preoperatively } \\
\text { Method of Feeding }\end{array}$} \\
\hline Breast & 45 & 90 & 0 & 0 & 9.045 & $0.000 * * *$ \\
\hline Bottle & 2 & 4 & 43 & 86 & 8.241 & $0.000 * * *$ \\
\hline Nasogastric & 3 & 6 & 7 & 14 & 1.333 & 0.091 \\
\hline Total: & 50 & 100 & 50 & 100 & & \\
\hline \multicolumn{7}{|c|}{$\mathbf{X}^{2}=83.956 * * * \quad$ P.Value $=0.0001$} \\
\hline \multicolumn{7}{|l|}{ Number of Feedings Daily: } \\
\hline $1-$ & 0 & 0 & 2 & 4 & 1.429 & 0.077 \\
\hline 4- & 7 & 14 & 22 & 44 & 2.928 & $0.002 * *$ \\
\hline 7- & 17 & 34 & 15 & 30 & 0.429 & 0.334 \\
\hline $10-$ & 11 & 22 & 10 & 20 & 0.246 & 0.403 \\
\hline $13-15$ & 15 & 30 & 1 & 2 & 3.819 & $0.000 * * *$ \\
\hline Total: & 50 & 100 & 50 & 100 & & \\
\hline \multicolumn{7}{|c|}{$\mathbf{X}^{2}=\mathbf{2 0 . 6 5 0} * * * \quad$ P.Value $=0.0001$} \\
\hline \multirow{2}{*}{\multicolumn{7}{|c|}{$\begin{array}{l}\text { B. Postoperatively } \\
\text { Method of Feeding }\end{array}$}} \\
\hline & & & & & & \\
\hline Breast & 42 & 84 & 0 & 0 & 8.510 & $0.000 * * *$ \\
\hline Bottle & 1 & 2 & 42 & 84 & 8.282 & $0.000 * * *$ \\
\hline Nasogastric Tube & 7 & 14 & 8 & 16 & 0.280 & 0.390 \\
\hline Total: & 50 & 100 & 50 & 100 & & \\
\hline \multicolumn{7}{|c|}{$X^{2}=81.160 * * * \quad$ P.Value $=0.0001$} \\
\hline Number of Feedings: & & & & & & \\
\hline $1-$ & 18 & 36 & 34 & 68 & 3.203 & $0.007 * * *$ \\
\hline $6-$ & 24 & 48 & 16 & 32 & 1.633 & $0.051 *$ \\
\hline $11-15$ Feeds & 8 & 16 & 0 & 0 & 2.949 & $0.0016 * *$ \\
\hline Total: & 50 & 100 & 50 & 100 & & \\
\hline & 4.52 & & & $=0.00$ & & \\
\hline
\end{tabular}

* P. Value $<0.05 \quad=$ Statistically Significant Difference

** P. Value $<0.01=$ High Statistically Significant Difference

*** P. Value $<0.0001=$ Very High Statistically Significant Difference

Wound healing process:

Table (4): Relationship between sound healing of neonates' wounds and their type of feeding during $7^{\text {th }}$ and $14^{\text {th }}$ day

\begin{tabular}{|l|l|c|c|c|c|c|}
\hline \multirow{2}{*}{ Sound healing Feeding } & \multicolumn{2}{|c|}{ Breast milk } & \multicolumn{2}{c|}{ Formula milk } & \multirow{2}{*}{$\mathbf{X}^{2}$} & \multirow{2}{*}{ P-Value } \\
\cline { 2 - 6 } & No. & $\%$ & No. & $\%$ & & \\
\hline $\mathbf{7}^{\text {th Day: }}$ & 18 & 36 & 5 & 10 & $8.131^{* *}$ & \multirow{2}{*}{0.004} \\
Yes & 32 & 64 & 45 & 90 & & \\
\hline Total & 50 & 100 & 50 & 100 & & \multirow{2}{*}{0.000} \\
\hline 14th Day: & 39 & 78 & 16 & 32 & $19.556^{* * * *}$ & \\
\hline Yes & 11 & 22 & 34 & 68 & & \\
\hline No & 50 & 100 & 50 & 100 & & \\
\hline
\end{tabular}

** P. Value $<0.01=$ High Statistically Significant Difference

*** P. Value $<0.0001=$ Very High Statistically Significant Difference 
Fig. (2) Distribution of Neonates According to their Occurrence of Wound Healing Sound

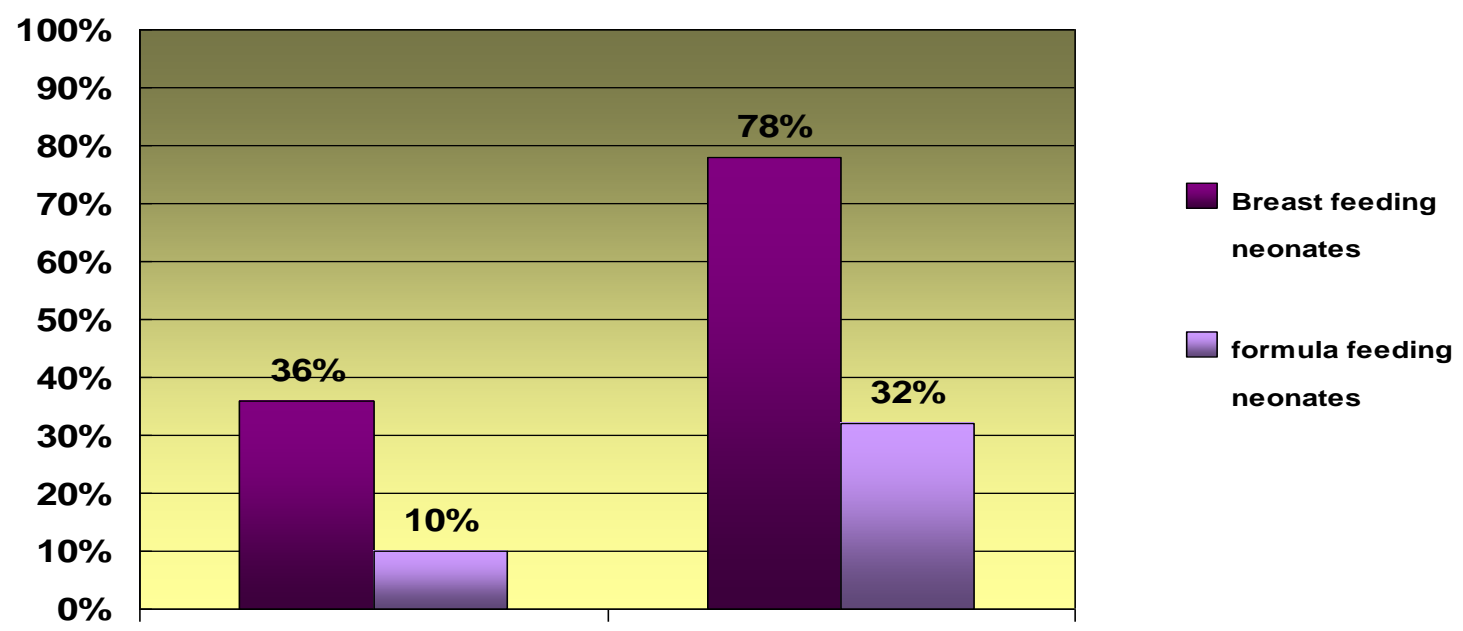

Table (5):Relationship between inflammation of neonates' wounds and their type of feeding during $7^{\text {th }}$ and $14^{\text {th }}$ day

\begin{tabular}{|l|c|c|c|c|c|c|}
\hline \multirow{2}{*}{ Inflammation Feeding } & \multicolumn{2}{|c|}{ Breast milk } & \multicolumn{2}{c|}{ Formula milk } & \multirow{2}{*}{$\mathbf{X}^{2}$} & \multirow{2}{*}{ P-Value } \\
\cline { 2 - 5 } & No. & $\mathbf{\%}$ & No. & \% & & \\
\hline 7th Day: & 15 & 30 & 29 & 58 & & \\
Yes: & 35 & 70 & 21 & 42 & $6.859^{* *}$ & 0.009 \\
No: & 50 & 100 & 50 & 100 & & \\
\hline Total: & 4 & 8 & 19 & 38 & & \\
\hline 14th Day: & 46 & 92 & 31 & 62 & $11.067^{* * *}$ & 0.000 \\
Yes: & 50 & 100 & 50 & 100 & & \\
No: & & & & & \\
\hline Total: & & & & & \\
\end{tabular}

** P. Value $<0.01=$ High Statistically Significant Difference

$* * *$ P. Value $<0.0001=$ Very High Statistically Significant Difference

Fig. (3) Distribution of Neonates According to their Occurrence of Wound Inflammation

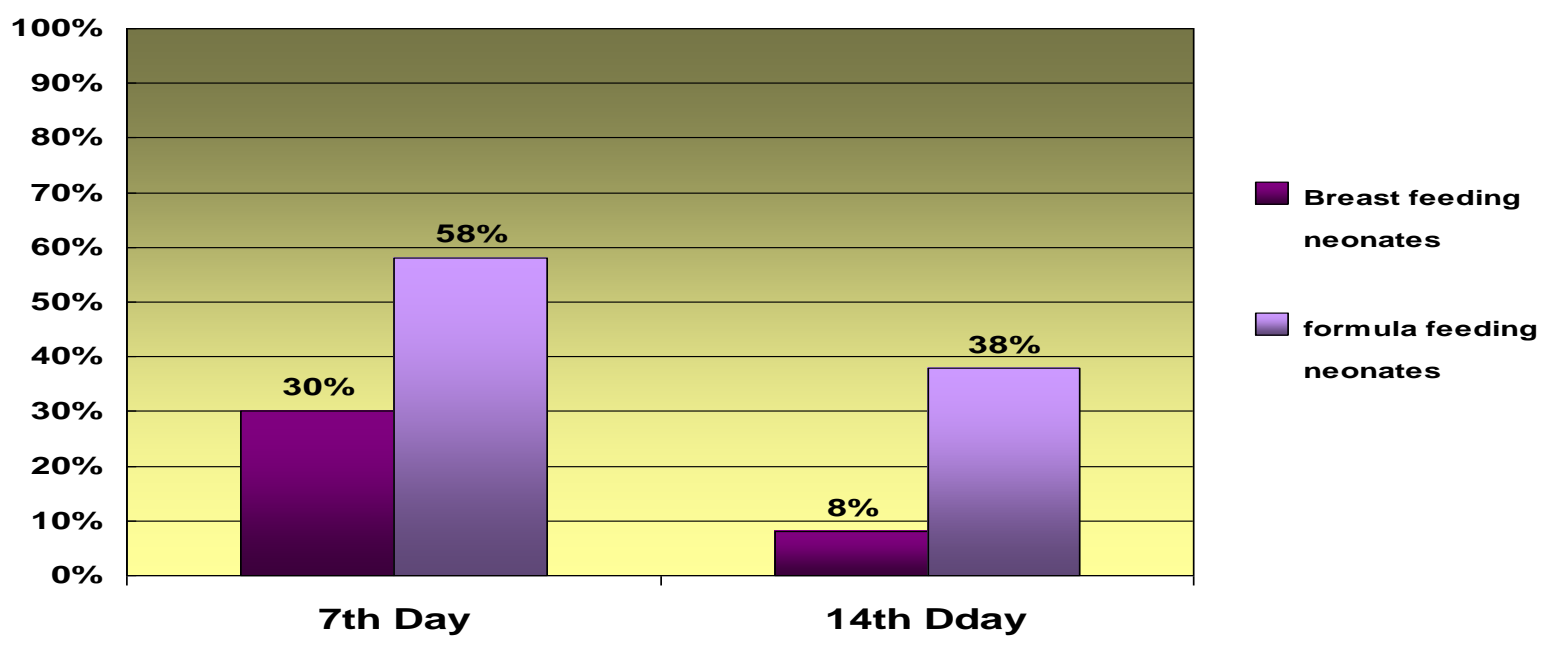


Table (6): Relationship between gapping of neonates' wounds and their type of feeding during $7^{\text {th }}$ and $14^{\text {th }}$ day

\begin{tabular}{|c|c|c|c|c|c|c|}
\hline \multirow{2}{*}{ Gapping $\quad$ Feeding } & \multicolumn{2}{|c|}{ Breast milk } & \multicolumn{2}{|c|}{ Formula milk } & \multirow[t]{2}{*}{$\mathbf{X}^{2}$} & \multirow[t]{2}{*}{ P-Value } \\
\hline & No. & $\%$ & No. & $\%$ & & \\
\hline $7^{\text {th }}$ Day: & & & & & & \\
\hline$\overline{\text { Yes: }}$ & 11 & 22 & 17 & 34 & 1.240 & 0.266 \\
\hline No: & 39 & 78 & 33 & 66 & & \\
\hline Total: & 50 & 100 & 50 & 100 & & \\
\hline 14 ${ }^{\text {th }}$ Day: & & & & & & \\
\hline Yes: & 7 & 14 & 17 & 34 & $4.441 *$ & 0.035 \\
\hline No: & 43 & 86 & 33 & 66 & & \\
\hline Total: & 50 & 100 & 50 & 100 & & \\
\hline
\end{tabular}

Table (7): Relationship between neonates with burst abdomen and their type of feeding during $7^{\text {th }}$ and $14^{\text {th }}$ day

\begin{tabular}{|c|c|c|c|c|c|c|}
\hline \multirow{2}{*}{$\mathrm{P}_{\text {Burst Abdomen }}^{\text {Feeding }}$} & \multicolumn{2}{|c|}{ Breast milk } & \multicolumn{2}{|c|}{ Formula milk } & \multirow[t]{2}{*}{$\mathrm{X}^{2}$} & \multirow[t]{2}{*}{ P-Value } \\
\hline & No. & $\%$ & No. & $\%$ & & \\
\hline $7^{\text {th }}$ Day: & & & & & & \\
\hline Yes: & 1 & 2 & 6 & 12 & 2.458 & 0.117 \\
\hline No: & 49 & 98 & 44 & 88 & & \\
\hline Total: & 50 & 100 & 50 & 100 & & \\
\hline $14^{\text {th }}$ Day: & & & & & & \\
\hline Yes: & 1 & 2 & 7 & 14 & 3.397 & 0.065 \\
\hline No: & 49 & 98 & 43 & 86 & & \\
\hline Total: & 50 & 100 & 50 & 100 & & \\
\hline
\end{tabular}

Table (8):Relationship between neonates with wound discharge (presence of discharge) and their type of feeding during $7^{\text {th }}$ and $14^{\text {th }}$ day

\begin{tabular}{|c|c|c|c|c|c|c|}
\hline \multirow{2}{*}{$\begin{array}{ll}\text { Items } & \text { Feeding } \\
\end{array}$} & \multicolumn{2}{|c|}{ Breast milk } & \multicolumn{2}{|c|}{ Formula milk } & \multirow[t]{2}{*}{$\mathbf{X}^{2}$} & \multirow[t]{2}{*}{ P-Value } \\
\hline & No. & $\%$ & No. & $\%$ & & \\
\hline \multicolumn{7}{|l|}{$7^{\text {th }}$ Day } \\
\hline$\overline{\text { Presence of Discharge: }}$ & & & & & \multirow{7}{*}{3.610} & \multirow{7}{*}{0.057} \\
\hline Yes: & 12 & 24 & 22 & 44 & & \\
\hline No: & 38 & 76 & 28 & 56 & & \\
\hline Total: & 50 & 100 & 50 & 100 & & \\
\hline Type of Discharge & & & & & & \\
\hline - Purulent & 6 & 50 & 13 & 59 & & \\
\hline - Non purulent & 6 & 50 & 9 & 41 & & \\
\hline \multicolumn{5}{|l|}{$14^{\text {th }}$ Day } & \multirow{7}{*}{$5.020 *$} & \multirow{7}{*}{0.025} \\
\hline Yes: & 3 & 6 & 12 & 24 & & \\
\hline No: & 47 & 94 & 38 & 76 & & \\
\hline Total: & 50 & 100 & 50 & 100 & & \\
\hline \multicolumn{5}{|l|}{ Type of Discharge: } & & \\
\hline - Purulent & 2 & 67 & 7 & 58 & & \\
\hline - Non purulent & 1 & 33 & 5 & 42 & & \\
\hline
\end{tabular}

$*$ P. Value $<0.05=$ Statistically Significant Difference 
Table (9): Relationship between neonates with wound discharge (site of discharge) and their type of feeding during $7^{\text {th }}$ and $14^{\text {th }}$ day.

\begin{tabular}{|c|c|c|c|c|c|c|}
\hline \multirow{2}{*}{$\begin{array}{ll}\text { Site of Discharge } & \text { Feeding } \\
\end{array}$} & \multicolumn{2}{|c|}{ Breast milk } & \multicolumn{2}{|c|}{ Formula milk } & \multirow[t]{2}{*}{$\mathbf{X}^{2}$} & \multirow{2}{*}{ P-Value } \\
\hline & No. & $\%$ & No. & $\%$ & & \\
\hline \multicolumn{7}{|l|}{$7^{\text {th }}$ Day } \\
\hline - Suture Only & 8 & 66.6 & 11 & 50 & & \\
\hline - Suture +Incision & 2 & 16.7 & 10 & 45.5 & 3.610 & 0.057 \\
\hline - Site of Drain Only & 2 & 16.7 & 1 & 4.5 & & \\
\hline \multicolumn{7}{|l|}{$14^{\text {th }}$ Day } \\
\hline - Suture Only & 0 & 0 & 4 & 33.3 & & \\
\hline - Suture +Incision & 2 & 66.7 & 7 & 58.4 & $5.020 *$ & 0.025 \\
\hline - Site of Drain Only & 1 & 33.3 & 1 & 8.3 & & \\
\hline
\end{tabular}

$*$ P. Value $<0.05 \quad=$ Statistically Significant Difference

Table (1) show that the distribution of breast milk feeding and formula feeding neonates according to their gestational age, birth weight, and sex. It's clear from table one that $44 \%$ of breast milk feeding neonates and about half of formula feeding neonates (48\%) gestational age ranged from $41-<42$ weeks. About half of breast milk feeding neonates (40\%) and only $16 \%$ of formula feeding neonates had birth weight ranged from $3.400-<3.700 \mathrm{~kg}$.

Regarding the sex it was found that the majority of breast milk feeding neonates $(78 \%)$ were males compared to $64 \%$ of formula feeding neonates.

Table (2) and Figure (1) show that the distribution of breast milk feeding and formula feeding neonates according to their diagnosis. It was found that the majority of the breast milk feeding (82\%) and formula feeding neonates (66\%) had a congenital disease, while only $18 \%$ of breast milk feeding neonates and $34 \%$ of formula feeding neonates had an acquired disease.

No statistical significant difference was present between type of neonates' feeding (breast milk feeding and formula feeding) and their diagnosis.

Table (3) clear that the relationship between sound healing of neonates' wounds and their type of feeding during $7^{\text {th }}$ and $14^{\text {th }}$ day.

A very high statistically significant difference was found between breast milk feeding and formula feeding neonates by breast and bottle (P.<0.0001), while no statistical significant difference was found between breast milk feeding and formula feeding neonates by nasogastric tube.

Regarding the number of daily feeds, a very high statistically significant difference was found between breast milk feeding and formula feeding neonates in the number of 13-15 feeds/day and 4-6 feeds/day (P. <0.0001). While the highest numbers of feeds $(13-15$ feeds/day) were found among breast milk feeding neonates during the preoperative period. The highest percentages of 4-6 feeds/day was found among formula feeding neonates.
Very high statistically significant difference was found between breast milk feeding and formula feeding neonates (P.<0.0001), while no statistical significant difference was found between feeding method of breast milk feeding and formula feeding neonates by nasogastric tube ( $\mathrm{P} .=0.390)$.

Regarding the number of daily feeds, a very high statistical significant difference was found between breast milk feeding and formula feeding neonates in the number of 1-5 feeds/day, 6-10 feeds/day, and 11-15 feeds/day.

$48 \%$ and $16 \%$ of $6-10$ feeds/day and $11-15$ feeds/day respectively were found among the breast milk feeding neonates, on the other hand $68 \%$ of $1-5$ feeds/day were found among the formula feeding neonates.

Table (4) and Figure (2) clear that relationship between sound healing of neonates' wounds and their type of feeding during $7^{\text {th }}$ and $14^{\text {th }}$ day

The high statistical significant difference $(\mathrm{P}<0.004)$ was found between occurrence of sound healing of neonate's wound and their type of feeding (breast milk feeding or formula feeding) and during the 7th day. It was found that, the percentage of occurrence of sound healing among the breast milk feeding neonates was more than one third $(36 \%)$ while the percentage of occurrence of sound healing among the formula feeding neonates was $10 \%$ only.

Very high statistically significant difference $(\mathrm{P}<$ 0.0001 ) was found between occurrence of sound healing of neonates' wounds and their type of feeding (breast milk feeding or formula feeding) during the 14th day. It was found that the majority (78\%) of breast milk feeding neonates wounds' had sound healing, while less than third (32\%) of formula feeding neonates wounds had sound healing during the 14th day.

Table (5) and Figure (3) revealed that the relationship between inflammation of neonates' wounds and their type of feeding during $7^{\text {th }}$ and $14^{\text {th }}$ day 
The high statistical significant difference (P. < 0.009) was found between occurrence of inflammation of breast milk feeding and formula feeding neonates' wound during the 7 th day. The majority $(58 \%)$ of formula feeding neonates' wounds were inflamed, less than one third $(30 \%)$ of breast milk feeding neonates' wounds were inflamed during the 7 th day.

Very high statistical significant difference (P. < 0.000) was found between occurrence of inflammation of wound and breast milk feeding and formula feeding neonates during the 14th day. About $38 \%$ of formula feeding neonates' wounds were inflamed, only $8 \%$ of breast milk feeding neonates' wounds were inflamed during the 14th day.

Table (6) Clear that the relationship between gapping of neonates' wounds and their type of feeding during 7 th and 14 th day.

There was no statistical significant difference $(\mathrm{P}<$ 0.266) was found between occurrence of gapping of breast milk feeding and formula feeding neonates' wounds during the 7 th day. Less than one quadrant $(22 \%)$ of breast milk feeding neonates' wounds were gapping, more than one-third (34\%) of formula feeding neonates' wounds were gapping during the $7^{\text {th }}$ day.

A statistical significant difference $(\mathrm{P}<0.035)$ was found between type of feeding and occurrence of gapping of breast milk feeding and formula feeding neonates' wounds during the 14th day.

Less than one quadrant (14\%) of breast milk feeding neonates' wounds was gapping, while more than one third $(34 \%)$ of formula feeding neonates' wounds were gapping during the $14^{\text {th }}$ day.

Table (7) revealed that the relationship between neonates with burst abdomen and their type of feeding during 7 th and 14th day.

Only two percent of breast milk feeding neonates had burst abdomen, while twelve percent of formula feeding neonates had burst abdomen during the 7 th day.

About one quadrant (14\%) of formula feeding neonates have burst abdomen, on the other hand only $2 \%$ of breast milk feeding neonates have burst abdomen during the 14th day.

There was no statistical significant difference was found between occurrence of burst abdomen among the breast milk feeding and formula feeding neonates and their type of feeding during $7^{\text {th }}$ and $14^{\text {th }}$ day

Table (8) Clear that the relationship between neonates with wound discharge (presence of discharge) and their type of feeding during 7 th and 14th day.

No statistical significant difference (P. < 0.057) was found between type of neonates' feeding (breast milk feeding or formula feeding) and occurrence of wound discharge during the 7 th day.

About $44 \%$ of wound discharge was found among the formula feeding neonates and $59 \%$ of them were purulent discharge compared to those with wound discharge $(24 \%)$ and $50 \%$ of them were purulent discharge among the breast milk feeding neonates during the 7 th day.

Statistical significant difference $(\mathrm{P}<0.025)$ was found between type of neonates' feeding (breast milk feeding or formula feeding) and occurrence of wound discharge during the $14^{\text {th }}$ day.

Small percentage of wound discharge (6\%) was found among the breast milk feeding neonates compared to those with wound discharge $(24 \%)$ was found among the formula feeding neonates during the 14 th day.

Table (9) Revealed that $20 \%$ of formula feeding neonates had discharge in this site of wound, while only $4 \%$ of breast milk feeding neonates had discharge in this place of the wound during the 7 th day.

No statistical significant difference $(\mathrm{P} .<0.057)$ was found between place of neonates' wound discharge and their type of feeding (breast milk feeding or formula feeding) during the 7 th day.

Statistical significant difference $(\mathrm{P} .<0.025)$ was found between place of neonates' wounds discharge and their type of feeding (breast milk feeding or formula feeding) during the 14th day.

Regarding the presence of wound discharge in suture only it was found that $8 \%$ of formula feeding neonates had discharge in this place of wound, while no one of breast milk feeding neonates had discharge in this place of the wound during the 14th day.

\section{Discussion:}

Nutrition plays a key role in the prevention and treatment of children's wounds and especially in newborns. Breast-feeding is such an amazing advantage for both a mother and child. It has long been established that both parties benefit from the antibodies and nutrients in breast milk (Center for Public Health Nutrition, 2010).

Majority of the cells in breast milk are macrophages, cells that kill bacteria, fungi and viruses. Breast milk feeding neonates are protected, in varying degrees, from a number of infectious cases as well as wound infection. Therefore, it promotes the process of healing and help in repairing of damaged tissues. Furthermore, mothers produce antibodies to whatever disease is present in their environment, making their milk custom-designed to fight the diseases their babies are exposed to as well (Rumel, 2009). 
In this study, it was observed that a very high statistically significant difference was found between breast milk feeding and formula feeding neonates in the number of feeds/day. The highest numbers of feeds were found among breast milk feeding neonates preoperatively. These results could be explained by one of the following; Firstly, increasing of neonate's pleasure sensation during sucking of the breast and emotional bonding between mother and neonate during breast-feeding more than bottle feeding. Secondly, because formula milk digested slower than breast milk, formula-fed babies usually need to eat less often than do breast milk feeding babies.

Results of the present study were in agreement with those obtained by the study of Labbok (2010) reported that the breast milk feeding babies under the age of six months have more frequency of feeding times than formula feed babies.

These results were in accordance with what mentioned by Bar-Yam (2008) added that the exclusively bottle-fed neonates showed fewer number of feeding and shorter duration of sucking and compared to breast milk feeding neonates.

These data showed that the healing process occurred rapidly and with correct manner and the wound infection occurred less in wounds of neonates who were receiving breast milk feeding than that

occurred in wounds of neonates who were receiving formula milk feeding and this may be related to antibodies that reach naturally to neonates from the mother during the breast-feeding and these antibodies are not found in formula milk.

In this study, it was observed that the highest percentage of maximum numbers of postoperative feeds reached by breast milk feeding neonates compared to formula feeding neonates.

Schack-Nielsen and Michaelsen (2006) mentioned that the most wounds will typically have less discharge with less blood in it until there is no discharge whatsoever and the wound has completely closed.The amount, smell and color of purulent discharge (pus) can determine the type of wound infection.

These results in agreement with the result of Reilly (2007) stated that the number of feeding times/day among the neonates with bottle-feeding was shorter in number and duration of feeding than breast milk feeding neonates post-surgery.

Stevens and Franck (2005) added that the poor nutrition makes it easier for wounds to develop, however good nutritional status is essential to promote effective growth and repair of body tissues. Nutrients play vital roles in the constitution of a wellbalanced diet and any depletion in a person's nutritional intake, can lead to malnutrition and protein-energy malnutrition, conditions that are known to have considerable impact on health and well-being and on the wound healing process.

The finding of the present study showed that the high and very high statistically significant difference was found between occurrence of sound healing of neonates' wounds and their type of feeding during the 7 th and 14th postoperative days respectively. On other hands, the majority of occurrence of sound healing from total healing was found among breast milk feeding neonates while about one third of occurrence of sound healing was found among formula feeding neonates during the 7 th and 14th postoperative days respectively. These results could be attributed to the fact that breast milk contains enough concentrations of all nutritional elements essential for healing.

Langer (2006) mentioned that the presence of infected fluid and microorganisms in the subcutaneous space leads to invasion of tissues by bacteria that would otherwise be directed towards the tissue repair and can cause burst abdomen. They also release enzymes that break down protein, which is an important component in wound repair.

High and very high statistically significant difference was found between occurrence of inflammation of breast milk feeding and formula feeding neonates' wounds during the 7 th and 14th postoperative days respectively. The majority of total inflamed cases numbers were in the formula feeding neonates' wounds, while about third from total inflamed cases number was breast milk feeding neonates during the 7 th and 14 th postoperative days respectively. These results could be due to including the breast milk of antibodies that enable the neonate body to overcome microorganism included at the neonates' wounds.

The results of the present study was consistent with Szeszycki and Benjamin (2005) reported that the breast milk has more lactose, which in the gut stimulates growth of microorganisms, which synthesize some B vitamins and produce organic acids that may retard growth of harmful bacteria and has more monounsaturated fatty acids, which enhance absorption of fat and calcium.

Chantry et al. (2006) mentioned that the infection-fighting antibodies passed from a nursing mother to her neonate could help to lower the occurrence of many infected conditions.

Pierro, (2006) reported that the breast milk help to protect breast milk feeding neonates from wound infection by enforcing neonates' immune system by increasing the barriers to infection and decreasing the growth of organisms like bacteria and viruses. 
Goulet, (2009) reported that breast-feeding is particularly beneficial for premature babies and may also protect children against many diseases. As a group, formula-fed neonates have more infections and more hospitalizations than do breast milk feeding babies.

Puligandla et. al (2008) mentioned that none of the important antibodies found in breast milk is found in manufactured formula milk which means that formula milk doesn't provide the neonate with the added protection against wounds infection and illness that breast milk does.

According to the American Academy of Pediatrics (AAP, 2007), human breast milk is preferred for all neonates. This includes even premature and sick babies, with rare exceptions. It is the food least likely to cause allergic reactions; it is inexpensive; it is readily available at any time of the day or night; babies accept the taste readily; and the antibodies in breast milk can help a neonate to resist infections and help to rapid wound healing.

Schlatter et al. (2006) stated that more than three quadrants of the cells that make up breast milk contain antibodies. It has long been established that both parties benefit from the antibodies and nutrients in breast milk promote the repairing of wound tissues.

\section{Conclusions:}

Based on the results of the current study it was concluded that the breast milk feeding neonates were received more frequency of feeding numbers daily than formula feeding neonates.

The breast milk feeding neonates have rapid sound healing of their wounds more than formula feeding neonates and wound inflammation or redness, wound discharge, gapping of wound, and burst abdomen occurred more in formula feeding neonates than in breast milk feeding neonates.

\section{Recommendations:}

Based on the findings of the current study, the following recommends were proposed:

- Stress on the mother to start exclusive breast milk feeding immediately after birth until six months from her neonate's age due to the advantage of breast milk feeding on her neonate's health and wound healing.

- Health educational classrooms must be giving to encourage mothers of surgical neonates during admission period at hospitals to maintain exclusive breast milk feeding until six months of neonate's age.

- Educational program should be introduced to the nurses about right techniques, advantage, and role of breast-feeding on increasing immunity, growth, and wound healing of infants.

- Educational program should be introduced to the nurses about right techniques, advantage, and role of breast milk feeding on increasing immunity, and wound healing of neonates.

- Encouraging the nurses to improve and update their knowledge about the effect of breastfeeding on wound healing by reading. This can be achieved by establishing a small nursing library in hospital departments supplied with recent Arabic textbooks, nursing periodicals and procedure manuals.

- Follow-up health educational sessions at out patient clinics during the follow up for wound care to stress on the previous knowledge.

\section{References:}

1.American Academy of Pediatrics (2007): Breastfeeding and the use of human milk, Pediatrics (15):496, 500.

2. Bar-Yam N (2008): Workplace lactation support, part 1: a return-to-work formula-feeding, J Hum Lact 14:249, 254.

3. Browne N, Laura M., Flanigan, C. McComiskey, and Lynne D. (2007): Nutrition in the Pediatric Surgical Patient, Nursing Care of the Pediatric Surgical Patient and Wound Healing, 2nd ed., The United States of America: (3) pp 32-33, 40.

4. Center for Public Health Nutrition (2010): Child Care and infection Prevention by breastfeedingding.Sitedat;http://depts.washington. edu/uwcphn/work/child/childcare.html.

5. Chantry C, Howard C, and Auinger P (2006): Full breastfeeding and formula feeding duration and associated decrease in respiratory tract infection in US children and infection-fighting antibodies. Pediatrics 117(2):425.

6. Duque-Estrada E, Duarte $M$, Rodrigues $D$, and Raphael M (2003): Wound infections in pediatric surgery: a study of 575 patients in a university hospital, Pediatric Surge Int. Journal; 19 (6): 436, 440.

7. Goulet $O$ (2009): Effect of human milk against infection in Short bowel syndrome infants in pediatric patients. Nutrition, 14, 784, 790.

8. Labbok M. (2010): Breastfeeding, Formula use and Health: Cost effectiveness and cost benefits, American Academy of Pediatrics. Sited at; http://pediatrics.aappublications.org/cgi/eletters/pe ds.

9. Langer J. (2006): Anti-microbial effect of breast milk. Journal of Pediatric Surgery, 5(2), 124.

10. Letizia M., O'Leary J. and Vodvarka J. (2006): Neonatal Surgery: Perioperative nursing 
considerations. MedSurg Nursing, 12(2), 111-112, 115,120 .

11. Pierro A. (2006): Metabolism and nutritional support in the surgical neonate. Journal of Pediatric Surgery, 37, 811, 812.

12. Puligandla $P$, Janvier $A$. and Flageole $H$. (2008): Contemporary postnatal surgical management strategies for congenital abdominal wall defects. Volume 17, Issue 4, Pages 222. Sited at http://www.sempedsurg.org/article/S10558586(08)00051-6/abstract.

13. Reilly J. (2007): Evidence-based surgical wound care on surgical wound infection. British Journal of Nursing (Tissue viability supplement) 11(16): S44, S50, S56.

14. Rumel S. (2009): Breast milk is the optimal form of baby nutrition. Sited at: http://www.rumela.com/diary/diary_baby_care.htm

15. Sanchez A (2007): Patterns and correlates of metabolism and nutrition management in surgical neonates, Am J Prev. Med 32(2): 124.

16. Schack-Nielsen $L$ and Michaelsen $K$ (2006): Breast feeding and future health, Can Opin Clin Nutr Melab Care 9(3):289, 290.

17. Schlatter M, Norris $K$, and Uirvlugt $N$ (2006): Improved outcomes in the treatment of gastroschisis using a preformed silo and delayed repair approach, J Pediatr Surg 38(3):459.

18. Shulman R. and Phillips S. (2008): Enteral and parenteral nutrition. Pediatric gastro-enterology and nutrition in clinical practice. 1st ed., New York: Marcel Dekker. pp. 417, 419, 421.

19. Stevens B. and Franck L. (2005): Special needs of pre term infants in the management of pain and discomfort. Journal of Obstetric and Gynecologic Neonatal Nursing, 24, 856.

20. Szeszycki E and Benjamin S (2005): Time and frequency of feedings. In G. Cresci (Ed.), Nutrition support for the critically ill patient (pp. 303-304, 309).

21. Ziegler M, Richard G, Azizkhan M, Thomas R, and Weber D (2003): Enteral and Parenteral Nutrition after Surgical, Role of Nutrition on Growth Operative Pediatric Surgery, 1st ed., United States, San Francisco:Lisbon, (7), pp.76, 88. 